\title{
SELEÇÃO DE MATRIZES DE Tabebuia roseoalba (RIDL) Sandwith COM USO DE MÉTODO DE PONTUAÇÃO DE VARIÁVEIS NA ARBORIZAÇÃO URBANA DE MARINGÁ-PR.
}

\author{
Alexandrina Pujals ${ }^{1}$, André César Furlaneto Sampaio ${ }^{2}$, Oscar Theodoro da Silva Neto $^{3}$, Jane \\ Moreschi $^{4}$
}

(recebido em 09.10.2008 e aceito para publicação em 26.03.2009)

\begin{abstract}
RESUMO
Maringá é lembrada por ter uma arborização urbana exuberante, mas a "qualidade" desta vem decaindo há anos, devido a fatores diretamente ligados a manutenção e planejamento dessa arborização. Sabendo que a procedência das sementes a serem utilizadas para arborização urbana é um fator fundamental para boa qualidade das mudas e garantia de diversidade genética, este trabalho objetivou analisar a população de Tabebuia roseoalba (Ridl) Sandwith nas vias públicas da cidade a fim de determinar árvores matrizes para coleta de sementes. Elaborou-se um sistema de avaliação utilizando parâmetros (variáveis) da copa, do tronco, da base do tronco, da localização, do porte das árvores e do índice biométrico para assim, definir um índice final, que foi considerado para classificar as árvores como matrizes. Foi calculado também o tamanho efetivo da população e depois o número de matrizes necessárias, perfazendo um total de 24 matrizes necessárias. Das 583 árvores visitadas, 102 possuem os requisitos necessários para serem matrizes, destas foram selecionadas 24 , com base nos vários parâmetros analisados e no índice biométrico. Este estudo demonstrou que a determinação de matrizes urbanas através do sistema de pontuação proporciona eficiência para se eleger indivíduos por meio de vários parâmetros quali-quantitativos simultaneamente.
\end{abstract}

Palavras-chave: bignoniaceae, Tabebuia roseoalba, arborização urbana, matrizes, silvicultura urbana.

\footnotetext{
${ }^{1}$.Bióloga, Especialista em Gestão dos Recursos Naturais, Avenida 15 de Novembro, no 171 - Apto 903, Bairro Centro, Maringá - PR, CEP: 87103-320. E-mail: ale.pujals@gmail.com

2.Engenheiro Florestal, Mestre em Geografia, Maringá, Paraná, sampaio.andre@gmail.com

3.Engenheiro Agrônomo, Cianorte, Paraná, oscar.theodoro@gmail.com

${ }^{4}$. Bióloga, Maringá, Paraná, jane moreschi@hotmail.com
} 


\title{
MATRICES ELECTION OF Tabebuia roseoalba (RIDL) SANDWITH WITH USE OF VARIABLE PUNCTUATION METHOD IN URBAN ARBORIZATION OF MARINGÁ-PR.
}

\begin{abstract}
Maringá city is known for it's exuberant urban forestry, but this quality is decaying along the years, due to factors like maintenance and projection of it's arborization. As known, the used proceed of the seeds in urban forestry is an essential factor to obtain a good quality of the seedlings and to guarantee their genetic diversity. This study has the objective to analyze the Tabebuia roseoalba (Ridl.) population in streets and avenues of Maringá city to stipulate matrix for gathering their seeds. A system of evaluation was made profiteering parameters like top, trunk and lower part of the tree, besides localization, dimension and biometrical rate. After all, it is defined a final note, which is used to classify matrix trees. The effective size of population was calculated, than the number of matrix trees necessary, totalizing 24 matrix trees. From the 583 inspected trees, 53 had good parameters to consider matrix, from these, 24 were selected, to be a matrix, in base of biometrical rate and all the others parameters. This study work concluded that determination of urban matrix trees through the evaluation system proposed, affords efficiency to elect matrix trees with quality and quantity parameters concomitantly inside urban forest.
\end{abstract}

Key-words: bignoniaceae, Tabebuia roseoalba, urban forestry, matrix trees, Maringa. 


\section{INTRODUÇÃO}

A cidade de Maringá é lembrada por ter uma arborização urbana exuberante, mas a "qualidade" da mesma vem decaindo há anos, devido a vários fatores diretamente ligados a manutenção, planejamento e manejo dessa arborização.

Milano (1988) realizou o primeiro inventário na arborização urbana de Maringá e já apontava alguns problemas graves no manejo e planejamento. Sampaio (2006) que realizou inventário censitário (Censo Verde) nas árvores de vias públicas de Maringá constatou que a situação desta arborização está extremamente agravada, sendo que das 93.261 árvores analisadas, 35,25\% estavam em condições gerais sofríveis, ou seja, em estado geral de declínio, podendo apresentar severos danos decorrentes de pragas, doenças ou danos físicos sérios.

Nos últimos dois anos, após ser constatada a gravidade dos problemas na arborização, muitas ações para melhoria da mesma foram realizadas, podendo citar como ação principal a elaboração do Plano Diretor de Arborização Urbana de Maringá-PR, onde basicamente foram determinadas diretrizes e ações que estão direcionando o gerenciamento da arborização de vias públicas e organizando as necessidades emergenciais.

Dentre as espécies citadas pelo Plano Diretor de Arborização Urbana de Maringá, como prioritárias na composição da cidade, a espécie Tabebuia roseoalba (Ridl) Sandwith (Ipê-branco) consta como sendo uma das principais, sendo prevista a necessidade de produção de 10 mil mudas para serem plantadas nas ruas de Maringá, de acordo com a Prefeitura Municipal de Maringá (PMM, 2007).

A espécie Tabebuia roseoalba (Ridl.) Sandwith, pertencente à família Bignoniaceae, conhecida como Ipê-branco, possui uma altura que varia de 7 a 13 metros e seu tronco possui um diâmetro médio de 40 a $50 \mathrm{~cm}$. Possui copa piramidal, tronco ereto e exuberância em sua floração, além de ser xerófita e heliófila. Produz muitas sementes anualmente nos meses de outubro e novembro, e se postas pra germinar logo que colhidas, sua germinação fica acima de 40\% (LORENZI, 1992). De acordo com Sampaio (2006), a população total de Tabebuia roseoalba (Ipê-branco), na cidade de Maringá, é de 1.075 indivíduos distribuídos em vários logradouros da cidade. A freqüência atual desta espécie dentro da cidade é de apenas $1,15 \%$.

Sabendo que a procedência das sementes a serem utilizadas é um fator fundamental para boa qualidade das mudas e garantia de diversidade genética, este trabalho teve o 
intuito de analisar a população de Tabebuia roseoalba (Ipê-branco) nas vias públicas da cidade a fim de determinar árvores matrizes para coleta de sementes.

\section{MATERIAL E MÉTODOS}

\section{Descrição da área de estudo}

O município de Maringá situa-se entre as coordenadas geográficas $23^{\circ} 25^{\prime} 30^{\prime \prime}$ Sul e 51 56' 20" Oeste, no Paraná, com 487 km² e 325.968 habitantes (IBGE, 2007). O clima, segundo a classificação de Köppen (1978) é do tipo subtropical Cfa, com verões quentes, geadas pouco freqüentes e chuvas abundantes no verão. De acordo com o delineamento de Maack (1968) e adotando o Sistema Fisionômico-Ecológico de Classificação da Vegetação Brasileira, proposto por Veloso e Goes-Filho (1982), o município de Maringá-PR enquadrase na região fitogeográfica denominada de Floresta Estacional Semidecidual.

Os solos mais comuns na região de Maringá são: Nitossolo vermelho, o Latossolo Roxo, o Latossolo Vermelho-Escuro e os Neossolos Litólicos (EMBRAPA, 2006).

\section{Delineamento do estudo}

Objetivando definir uma quantidade suficiente de matrizes e sementes que mantivessem a diversidade genética existente na população de Tabebuia roseoalba (Ipêbranco) em Maringá, foi calculado o tamanho efetivo da população e depois o número de matrizes necessárias. Foram utilizadas para os cálculos as equações propostas por Cockerham (1969) e utilizadas e citadas por Sebbenn (2002) e Yamamoto et al. (2007):

$$
\mathrm{Ne}_{(1)}=0,5 /\{q[(\mathrm{n}-1) / \mathrm{n}]+[(1+\mathrm{F}) /(2 \mathrm{n})]\}
$$

Sendo:

Ne (1) - tamanho efetivo da população;

n - número total de progênies da população, ou sementes a serem coletadas;

$\mathbf{F}$ - coeficiente de endogamia da população ou do conjunto de progênies;

$\mathbf{q}$ - coeficiente de parentesco entre plantas dentro de progênies. 
A quantidade necessária de matrizes foi calculada pela equação:

$$
\mathrm{m}=\mathrm{Ne} I \mathrm{Ne}(1)
$$

Onde:

m - o número de matrizes;

Ne - valor teórico de tamanho efetivo;

$\mathrm{Ne}{ }_{(1)}$ - tamanho efetivo da população.

\section{Avaliação e cadastro das árvores}

Através de dados da Prefeitura Municipal de Maringá (PMM, 2007) foi verificada a localização dos indivíduos de Tabebuia roseoalba nos logradouros da cidade. Foram selecionados os logradouros (vias) em que a espécie Tabebuia roseoalba (Ipê-branco) fosse predominante, ou seja, não fosse vinda de plantios irregulares. Isso foi feito para excluir da população a ser analisada indivíduos que não estivessem de acordo com o planejamento de composição florística determinado pelo Plano Diretor de Arborização da Cidade.

Após a determinação das vias,as árvores foram visitadas e avaliadas entre os meses de novembro/2007 e março/2008, época em que estavam com folhas. A avaliação foi feita através de adequações na metodologia de Seitz (2006), para avaliação de riscos de queda de árvores.

No sistema de avaliação elaborado, utilizou-se principalmente de avaliações da copa, do tronco, da base do tronco, da localização e do porte, para assim, definir um índice final, que foi considerado para classificar as árvores como matrizes.

\section{Sistema de avaliação}

Objetivando-se executar um método de avaliação por pontuação de variáveis foram analisados vários itens por árvore, que representaram à localização, porte e condições gerais (qualidade). A localização foi analisada, pois aquelas localizadas em locais que prejudicam o planejamento urbano ou não são adequadas às características da espécie, acabam por ser removidas e não servirão por muito tempo como matrizes. Na avaliação das condições gerais das árvores, observou-se problemas de cunho genético e também o estado fitossanitário, que não são necessariamente genéticos, mas podem acarretar 
produção de sementes irregulares ou indicarem que a árvore poderá ser removida em pouco tempo. Vários aspectos podem ser observados, porém, as vezes são de alta subjetividade, dessa forma foram escolhidos os aspectos que podem ser verificados com maior objetividade em campo. Para cada item qualificador avaliado, foi atribuído uma nota de risco em relação à fitossanidade e risco de remoção da árvore. A escala utilizada variou de $1=$ pouca importância ou pouco risco a $5=$ muito importante ou alto risco e para considerar a ausência de importância foi utilizado o valor 0 . Os fatores avaliados ficaram divididos da seguinte forma:

\section{Localização}

- Número da árvore (NA) - Número que identifica a árvore por rua seguindo a seqüência de campo.

- Logradouro (Via) - Nome da rua, avenida, praça, etc.

- Número do imóvel (NI) - Número do imóvel em frente ao registro cadastrado.

- Distanciamento de postes - Dado que qualifica a localização e posicionamento da árvore, utilizado para indicar reposição ou não. Foi separado nas seguintes categorias e pontuações:

$<$ 1,5 metros - Qualificado como distanciamento péssimo. Pontuado com nota 5;

1,5 até 3,0 metros - Qualificado como distanciamento ruim. Pontuado com nota 3;

> 3,0 metros - Qualificado como bom distanciamento. Pontuado com nota 1;

Quando a árvore analisada não se apresentava do lado da rua com fiação esta recebia nota 0 , indicando a ausência do elemento.

- Distanciamento de esquinas - Dado que qualifica a localização e posicionamento da árvore. Medição do centro do tronco da árvore até o centro do poste $(\mathrm{m})$. Foi separado nas seguintes categorias e pontuações:

< 1,5 metros - Qualificado como distanciamento péssimo. Pontuado com nota 5;

1,5 até 3,0 metros - Qualificado como distanciamento ruim. Pontuado com nota 3;

> 3,0 metros - Qualificado como bom distanciamento. Pontuado com nota 1;

Quando a árvore analisada não se apresentava na esquina esta recebia nota 0 , indicando a ausência do elemento para pontuação.

- Distanciamento de bocas de lobo - Dado que qualifica a localização e posicionamento da árvore. Medição do limite do tronco da árvore até o limite da boca de lobo $(m)$. Foi separado nas seguintes categorias e pontuações:

$<$ 1,0 metro - Qualificado como distanciamento péssimo. Pontuado com nota 5; 
$>$ 1,0 metro - Qualificado como distanciamento bom. Pontuado com nota 1;

Quando a árvore analisada não se apresentava próxima a uma boca de lobo (bueiro) esta recebia nota 0 , indicando a ausência do elemento para pontuação.

- Distanciamento de saída de veículos - Dado que qualifica a localização e posicionamento da árvore. Medição do limite do tronco da árvore até o limite da saída de veículo $(m)$. Foi separado nas seguintes categorias e pontuações:

$<$ 1,0 metro - Qualificado como distanciamento péssimo. Pontuado com nota 5;

$>$ 1,0 metro - Qualificado como distanciamento bom. Pontuado com nota 1;

Quando a árvore analisada não se apresentava próxima a uma saída de veículo esta recebia nota 0 , indicando a ausência do elemento para pontuação.

- Distanciamento do meio fio (m) - Dado coletado com trena, foi medida a distância do eixo do tronco da árvore até o meio fio. Quando se verificava distanciamento > ou igual a 1 metro, essa árvore obtinha nota 1 (bom distanciamento), pois dentro da área urbana muitas vezes é o máximo de distância que se pode ter. Quando o distanciamento do meio fio foi < que 1 metro a nota foi 5 (péssimo distanciamento), pois pode comprometer o equilíbrio da árvore.

- Distanciamento do lote fio (m) - Dado coletado com trena, foi medida a distância do eixo do tronco da árvore até a linha de divisa da calçada pública e o lote em frente à árvore. Quando se verificava distanciamento > ou igual a 2 metros essa árvore obtinha nota 1 (bom distanciamento), pois a espécie é perfeitamente viável para uma calçada de até 2,5 metros de comprimento. Quando o distanciamento foi $<2$ metros a nota obtida era 5 (péssimo distanciamento), pois a espécie não é indicada para calçadas estreitas, podendo ser substituída.

\section{Porte}

- Altura Total (H) - Altura foi estimada visualmente até a extremidade mais alta da árvore. A estimativa foi feita comparando a altura das árvores com a de estruturas urbanas como postes, carros e prédios.

- Altura da Primeira Bifurcação (Hb) - Altura medida com trena do solo até a primeira bifurcação ou galho.

- Circunferência a Altura do Peito (CAP) - Em cada árvore avaliada foi medida a circunferência à altura do peito (1,3 $\mathrm{m}$ de altura) e no processamento dos dados, calculado o diâmetro à altura do peito. Nos casos de troncos múltiplos e bifurcados abaixo de 1,3 metros, todos foram medidos. As medições foram feitas com fitas métricas. 


\section{Avaliação da copa}

- Galhos secos (podres) - ocorrência de galhos secos (podres). Galhos finos (< 5 $\mathrm{cm} \varnothing$ ) ou secos sem apodrecimento) risco 1 a 5 para galhos grandes $(\varnothing>5 \mathrm{~cm}$ ) ou com sinais de apodrecimento (Os diâmetros dos galhos forma analisados visualmente, através da experiência de campo). Risco 0 quando não foram verificados galhos secos ou podres.

- Galhos angulados - foi verificada a existência de galhos que apresentam angulação pronunciada, principalmente no sentido vertical. Estes galhos têm potencial de ruptura longitudinal, com posterior quebra. Risco 1 para galhos finos $(\varnothing<5 \mathrm{~cm})$ a 5 para galhos grossos $(\varnothing>20 \mathrm{~cm}$ ). Risco 0 quando não foram verificados galhos angulados. Os diâmetros dos galhos foram analisados visualmente, através da experiência de campo.

- Galhos esguios, folhagem só na extremidade - as podas mal executadas muitas vezes levam à formação de galhos esguios com folhagem apenas na extremidade (na literatura inglesa definido como "rabo-de-leão"). Estes galhos são flexíveis, podendo vir a quebrar ou a interferir na rede. Risco 1 para galhos $<1 \mathrm{~m}$ a 5 para galhos $>3 \mathrm{~m}$. Risco 0 quando não foram verificados galhos esguios.

- Fungos - foi identificada a presença de corpos frutíferos de fungos nas cascas de galhos das copas, o que indica deterioração da madeira do interior. Quando identificado foi atribuído risco 5 .

- Folhagem rala - cada espécie arbórea tem um padrão de cor da folhagem, que pode variar durante o período vegetativo. Em condições de estresse, as árvores tendem a produzir menos folhas, de tamanho menor e às vezes de coloração mais pálida. Foi avaliado, pois é um indicativo de problemas no enraizamento das árvores ou outros distúrbios que afetam a fisiologia da árvore. Risco 1 para coloração mais clara até 5 para poucas folhas vivas. Risco 0 quando não foram verificadas alterações.

- Poda unilateral e drástica - foram identificadas as podas executadas retirando de apenas um lado da copa ou a retirada completa da copa. Essas podas comprovadamente provocam queda de árvores, pois influem diretamente nas condições do enraizamento. Normalmente os malefícios dessas podas não são imediatos, mas o potencial existe. Risco 4 para pouco desequilíbrio até 5 para copas extremamente desequilibradas ou poda drástica. Risco 0 quando não foram verificadas podas drásticas ou unilaterais. 


\section{Avaliação do tronco}

- Cavidades - foram avaliadas as extensões das cavidades visualmente, comparando as cavidades observáveis com o tamanho do tronco. Quando a cavidade ocupava menos de $70 \%$ do interior do tronco considerou-se que há estabilidade suficiente do lenho remanescente para sustentar a copa. Se a cavidade for na base da árvore, poderá haver o comprometimento das raízes, porém isto foi analisado em outra etapa. Risco 1 para ocos com comprometimento menor que $50 \%$ da área transversal, risco 3 para comprometimento de 50 a $70 \%$ e risco 5 para comprometimento acima de $70 \%$. Risco 0 quando não foram verificadas cavidades.

Foi considerado apenas o comprometimento visível na árvore, muitas vezes árvores com oco podem estar com o restante do interior do tronco também comprometido, mas esta possibilidade não pode ser verificada, pois precisa-se de equipamentos especiais. As análises foram todas visuais, da mesma forma que profissionais fazem em muitas prefeituras (para análise de pedido de corte), utilizando-se muito de experiência de campo das equipes.

- Orifícios de insetos (Cupins) - observou-se a presença de insetos no tronco através da visualização de orifícios de eclosão, de respiração e eliminação de resíduos, pela "serragem" ou "farelo" acumulada na base da árvore ou ainda por gotas ou exudação de gomas ou resinas. Considerou-se que presença dos insetos indica problemas com a árvore, embora nem sempre isto signifique um risco elevado de queda. Principalmente os cupins presentes nas árvores indicam cavidades e madeira em decomposição, normalmente conseqüência de lesões antigas. Risco 1 para poucos orifícios (orifícios que não englobam nem $10 \%$ da área do tronco - análise visual) a 5 quando muitos orifícios são visíveis no tronco (orifícios que englobam mais de $10 \%$ da área do tronco), ou quando ninhos arborícolas e muitos caminhos de cupins estão instalados na árvore (observando-se também ninhos nas copas). Risco 0 quando não foram verificados os diversos sinais mencionados.

- Fungos - assim como os insetos, a presença de corpos frutíferos de fungos são sinais evidentes de deterioração da madeira no interior do tronco. Quando observado fungo o risco foi considerado 5 .

- Cancro - O cancro pode ser definido como um sintoma associado à presença de fungos (Sphaeropsis sapinea, Phytophthora spp., Cryphonectria cubensis, Valsa ceratosperma, Botryospheria e outros), normalmente se apresenta como uma lesão margeada de calos, com a morte do câmbio e de parte da circunferência do tronco. 
Usando as determinações de Castro (2004), consideramos para avaliação que:

Cancros com até $200 \mathrm{~cm}^{2}$ - risco 1,0;

Cancros de $201 \mathrm{~cm}^{2}$ até $1000 \mathrm{~cm}^{2}$ - risco 2,0;

Cancros de $1001 \mathrm{~cm}^{2}$ até $5000 \mathrm{~cm}^{2}$ - risco 3,0;

Cancros de $5002 \mathrm{~cm}^{2}$ até $10000 \mathrm{~cm}^{2}$ - risco 4,0;

Cancros com mais de $10001 \mathrm{~cm}^{2}$ ou 50\% do tronco atingido - risco 5,0;

Risco 0 quando não foram verificados cancros.

- Injúrias mecânicas - Certas injúrias provocadas por vandalismos nas árvores podem provocar danos à saúde da árvore. Consideramos para nossa avaliação as seguintes determinações:

Desenhos e escritos no tronco - risco 1,0;

Pregos ou pequenos objetos presos ao tronco - risco 2,0;

Vestígios de fogo em parte considerável do tronco (20\%) - risco 3,0;

Injúria de $20 \%$ até $40 \%$ do tronco - risco 4,0;

Anelamento por injúria ou fogo ou mais de $50 \%$ do perímetro do tronco prejudicado risco 5,0; Risco 0 quando não foram verificadas injúrias mecânicas.

\section{Avaliacão da base do tronco}

Esta verificação foi considerada crucial para avaliação geral da árvore, pois a base do tronco e as raízes são fundamentais para a estabilidade. Na maioria das vezes as quedas das árvores estão associadas a danos nas raízes. Como é difícil avaliar o estado destas, utilizam-se indicadores indiretos, observando-se a base do tronco. Foram avaliados os seguintes aspectos:

- cavidades (preservação das raízes, até o solo) - cavidades na base do tronco afetam a circulação da seiva até as raízes e a estabilidade da árvore. É uma das principais causas de queda de árvores. Determinou-se risco 1 para cavidades com menos de 50\% de comprometimento e fechadas na base a 5 com cavidades acima de $70 \%$ e abertas na base. Risco 0 quando não foram verificadas cavidades;

- fungos - a presença de corpos frutíferos é sinal de problemas graves, indicam a presença de matéria morta, sendo a base do tronco intimamente ligada com as raízes considerou-se risco 5 quando observada a presença de fungos e 0 quando não verificados;

- espaço permeável (Área livre) - foi avaliado se a árvore tem espaço para desenvolver adequadamente suas raízes e estruturas de sustentação. Espaços exíguos 
podem aumentar o risco de queda. Considerou-se risco 1 para espaços de 5 a $10 \mathrm{~m}^{2}, 3$ para espaço de $1 \mathrm{~m}^{2}$ até $1,5 \mathrm{~m}^{2}$ e 5 sem espaço;

- neilóide - a base da grande maioria das árvores tem uma forma geométrica denominada neilóide. Quando esta forma não é identificada, os troncos são cilíndricos até o contato com o solo, há indícios de aterramento das mudas no plantio ou posteriormente, devido a aterramento por obras, etc. Estes aterramentos podem danificar as raízes, levando à instabilidade da árvore, ou ocultar problemas na base do tronco original. Considerou-se risco 5 para ausência de neilóide e 0 quando foi verificada a presença do neilóide;

- raízes cortadas - poda de raízes é uma das maiores causas de queda de árvores. Podemos considerar que toda árvore que teve suas raízes podadas para se ajustar a canteiros em calçadas é uma árvore de risco. Esta poda também ocorre em função de escavações para passagem de tubulação subterrânea. Considerou-se risco 1 para até 2 raízes cortadas, risco 3 para mais que duas raízes cortadas até, risco 5 para raízes cortadas em toda a volta do tronco;

- elevação e fissuras nas calçadas - calçadas com fissuras ou elevadas significam solo compactado a ponto de não permitir a expansão da raiz naturalmente. Raízes em solos compactados utilizam-se da força do crescimento em diâmetro para abrirem espaço, normalmente em solos muito compactados essas acabam ficando com partes superficiais danificando calçadas. Solo compactado e raiz não se expandindo significa provável falta de equilíbrio nas árvores, pois o equilíbrio é dado pelas raízes laterais. Existem espécies que naturalmente possuem raízes superficiais ou tabulares (Delonix regia e Schizolobium $s p$.) esta quando encontradas em calçadas indicam um erro de planejamento, porém o Ipê Branco, em questão, possui raízes naturalmente subterrâneas;

Foi aplicado risco 0 quando não verificadas fissuras e nem elevações nas calçadas e 5 quando verificados esses indícios.

\section{Seleção das matrizes}

Os dados coletados na avaliação foram processados pelo software Microsoft Excel ${ }^{\circledR}$, onde se trabalhou as notas atribuídas. Cada indivíduo arbóreo avaliado (indivíduos adultos) recebeu uma nota final por grupo de parâmetro avaliado (localização, porte, copa, tronco e base do tronco). Essa nota final foi atribuída, para cada grupo de parâmetros analisado, como sendo a maior nota encontrada dentro dos diversos fatores avaliados, dessa forma se avaliou a qualidade da situação das árvores por grupo. Uma nota final por indivíduo foi inserida também, como sendo a maior nota encontrada em qualquer um dos grupos 
analisados, pois basta apenas um item com grau de risco elevado (nota alta) para haver um dano sério. Em relação ao porte, a nota final foi estabelecida em questão do Valor Biométrico. O valor biométrico ( $\mathrm{Vbm}$ ) foi calculado pela equação determinada por Silva Filho et al. (2002):

$$
\mathrm{Vbm}=(\mathrm{DAP} \times 0,60)+(\mathrm{Hb} \times 0,40)
$$

Onde,

DAP = diâmetro à altura do peito $(\mathrm{m})$;

$\mathbf{H b}=$ altura da primeira bifurcação $(\mathrm{m})$.

Ao contrário das outras notas, quanto maior o Valor Biométrico, mais qualidade foi relacionada á árvore. De todos os indivíduos avaliados, foram excluídos os com altura total menor que 3 metros, pois estes foram estabelecidos empiricamente por Sampaio (2006) como indivíduos jovens devido às espécies com esta altura na arborização urbana serem recém estabelecidas nas ruas.

Os indivíduos com notas finais por indivíduo entre 4 e 5 também foram excluídos, pois foram considerados com problemas sérios pela avaliação. As árvores restantes foram consideradas as mais apropriadas para serem matrizes para coleta de sementes, sendo que se deu prioridade para aquelas com maior valor biométrico e em seguida com menor ou nenhum valor na base do tronco.

\section{RESULTADOS E DISCUSSÃO}

\section{Distribuição da População de Tabebuia roseoalba na cidade}

Dos 1075 indivíduos de Tabebuia roseoalba, (ipê-branco), que existem na cidade (PMM, 2007) foram avaliados 583, (54\% de toda a população) correspondentes a todos os logradouros indicados no plano diretor como de predominância desta espécie, ou seja, que possuem no mínimo 10 árvores desta espécie. No total foram 36 logradouros visitados, verificando-se que 486 árvores são adultas (maior ou igual 3 metros de altura total) e 97 jovens (árvores inferiores a três metros de altura). 
A população de Tabebuia roseoalba enquadrou-se entre a fase jovem e adulta, não havendo indivíduos considerados senis. Isso indica que o plantio desta espécie na cidade esta crescendo e sua distribuição está relacionada a novos loteamentos residenciais.

Os indivíduos adultos estão distribuídos pela região central da cidade como Avenida Carneiro Leão, Rua Mem de Sá, Rua Saulo Porto Virmond, Rua Distrito Federal e também em alguns bairros nos limites da cidade como o Jardim Diamante, Conjunto Cidade Canção e Jardim Império do Sol. Dentre os bairros existe uma concentração significativa desta espécie nos Bairros Jardim Real, Parque Jardim Paraíso e Jardim Brasil. Estes bairros possuem perfil residencial e ainda estão em fase final de ocupação. A rua que apresentou o maior número de árvores foi a Rua Olinto Mariani com 47 indivíduos (Tabela 01), localizada no bairro Jardim Diamante, mais ao norte da cidade, sendo 12 indivíduos jovens e 33 adultos.

Tabela 1. Quantidade de árvores por logradouro analisado

\begin{tabular}{lccccc}
\hline Tipo & & Quant. & Tipo & & Quant. \\
& Logradouro & Árvores & & Logradouro & Árvores \\
\cline { 5 - 6 } Rua & Olinto Mariani & 47 & Rua & Nestor M. Souza & 16 \\
Rua & Mem de Sá & 35 & Rua & Rio Ligeiro & 14 \\
Rua & Rubi & 35 & Rua & Rio Itapemirim & 12 \\
Rua & Esmeralda & 34 & Av. & Jose Alves dos Santos & 12 \\
Rua & 48016 & 30 & Av. & Guedner & 12 \\
Av. & Carneiro Leão & 27 & Rua & 7111 & 11 \\
Rua & Abelardo José Cruz & 26 & Rua & Antonio Franco de Morais & 10 \\
Rua & Ametista & 23 & Rua & Regina Celestino & 10 \\
Rua & Turquesa & 22 & Rua & Londrina & 10 \\
Rua & Saulo Porto Virmond & 20 & Av. & Joaquim Duarte Moleirinho & 10 \\
Rua & João C. Pereira & 20 & Rua & Citrino & 8 \\
Av. & Avenida das Torres & 20 & Rua & Rio Japuratuba & 7 \\
Av. & Tuiuti & 18 & Rua & Pintassilgo & 7 \\
Rua & Quartzo & 17 & Rua & Rosa Rubini & 7 \\
Rua & Distrito Federal & 17 & Av. & Colombo & 5 \\
Rua & Antonio C. Guimarães & 16 & Rua & Rio Jaguaribe & 5 \\
Rua & Darville Huergo & 16 & Rua & Camomila & 4 \\
\hline & & Total & & & 583 \\
\hline
\end{tabular}




\section{Análise dos parâmetros de distanciamento de estruturas urbanas de interesse}

Foram analisadas 486 árvores consideradas adultas nos diversos parâmetros e variáveis citados na metodologia. Em relação ao distanciamento de estruturas urbanas (Saída de Veículos, Postes, Bueiros e Esquinas) que influenciam na possível retirada ou não da árvore e em sua fitossanidade a figura 1 demonstra os resultados.

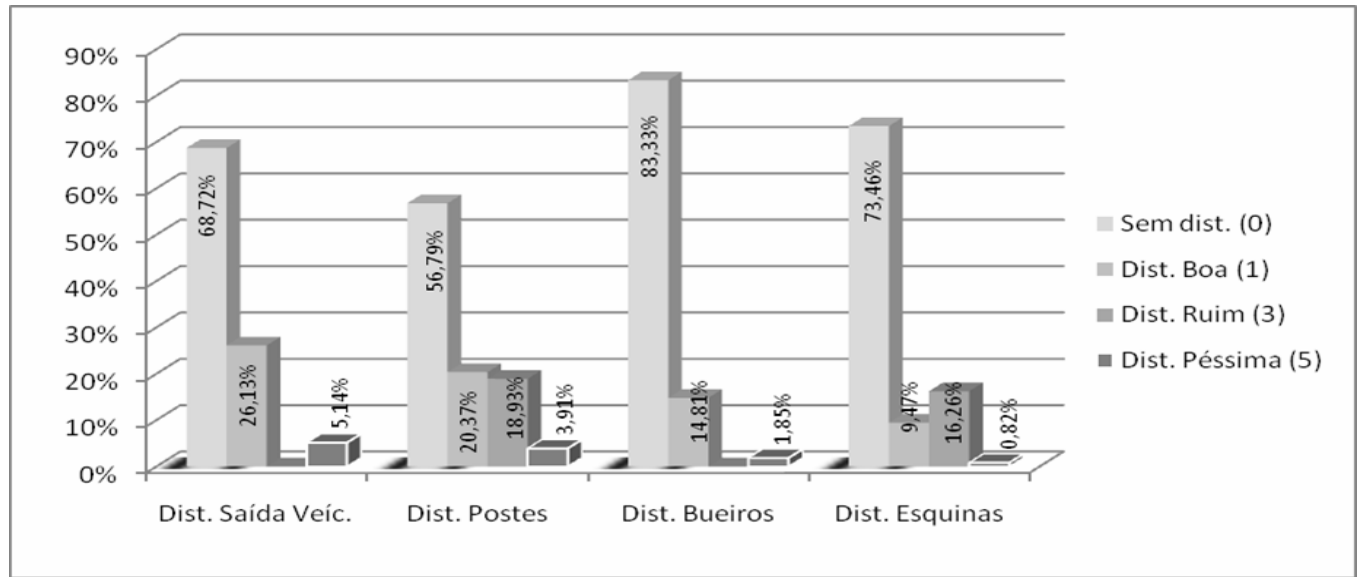

Figura 1. Porcentagens sobre a distribuição de notas dos parâmetros avaliados de distanciamento entre estruturas urbanas (Saída de Veículos, Postes, Bueiros e Esquinas) avaliados na população adulta de Tabebuia roseoalba analisada.

Sobre o distanciamento das árvores em relação à saída de veículos foi analisado que das 486 árvores avaliadas $334(68,72 \%)$ não estavam localizadas próximas a saída de veículos, ou seja, o restante (152 árvores) se localizavam próximas e tiveram suas distâncias medidas. Dessas 152 árvores avaliadas 127 (26,13\% das 486 avaliadas) estavam com o distanciamento bom ( $>$ ou $=1$ metro de distância da saída de veículos) e 25 (5,14\%) estavam com o distanciamento péssimo (<1 metros de distância da saída de veículos). Dessa forma a maioria das árvores avaliadas (152) estavam dentro do padrão e foram estabelecidas nessa variável como adequadas para serem matrizes.

Sobre o distanciamento de postes podemos verificar que 111 árvores (22,84\% das 486 avaliadas), ou seja, a maior parte das árvores de interesse (próximas a postes), estão fora do padrão e foram estabelecidas nessa variável como inadequadas para serem matrizes.

Em relação ao distanciamento das bocas de lobo (bueiros) 72 árvores (14,81\% das 486 avaliadas), sendo a maioria das árvores de interesse (próximas a bocas de lobo), ficaram como estando com bom distanciamento (> ou = a 1 metro de distância do bueiro). 
O distanciamento de esquinas teve a maioria das árvores de interesse com notas ruins de distanciamento, somando 83 árvores $(17,08 \%$ das 486 avaliadas) com distanciamento ruim e péssimo, respectivamente entre 1,5 até 3 metros e menores que 1,5 metros.

\section{Análise dos parâmetros de avaliação na copa das árvores}

A tabela abaixo demonstra os resultados das notas (riscos) avaliados em vários parâmetros verificados nas copas das árvores dos indivíduos de interesse.

Tabela 2: Distribuição das notas dos parâmetros avaliados nas copas da população adulta de Tabebuia roseoalba, para a arborização da cidade de Maringá, PR.

\begin{tabular}{ccccccc}
\hline Risco (nota) & $\begin{array}{c}\text { galhos secos } \\
\text { (podres) }\end{array}$ & $\begin{array}{c}\text { galhos } \\
\text { angulados }\end{array}$ & $\begin{array}{c}\text { galhos } \\
\text { esguios }\end{array}$ & fungos & $\begin{array}{c}\text { folhagem } \\
\text { rala/cor } \\
\text { anormal }\end{array}$ & $\begin{array}{c}\text { poda } \\
\text { unilateral/ } \\
\text { drástica }\end{array}$ \\
\hline $\mathbf{0}$ & 363 & 243 & 405 & 481 & 351 & 477 \\
$\mathbf{1}$ & 71 & 122 & 54 & - & 56 & - \\
$\mathbf{2}$ & 42 & 94 & 25 & - & 52 & - \\
$\mathbf{3}$ & 7 & 22 & 1 & - & 17 & - \\
$\mathbf{4}$ & 2 & 5 & 1 & - & 8 & 9 \\
$\mathbf{5}$ & 1 & 0 & 0 & 5 & 2 & 0 \\
\hline Total & $\mathbf{4 8 6}$ & $\mathbf{4 8 6}$ & $\mathbf{4 8 6}$ & $\mathbf{4 8 6}$ & $\mathbf{4 8 6}$ & $\mathbf{4 8 6}$ \\
\hline
\end{tabular}

Os resultados da tabela 2 demonstram alguns poucos indivíduos classificados com notas (riscos) entre 4 e 5, que são consideradas ruins e desclassificam as árvores para serem matrizes. Muitas vezes um mesmo indivíduo pode apresentar uma avaliação ruim em mais de um parâmetro, mas para classificação final bastará apenas uma nota ruim para a desclassificação.

\section{Análise dos parâmetros de avaliação do tronco das árvores}

A tabela 3 demonstra os resultados das notas (riscos) avaliados em vários parâmetros verificados nos troncos das árvores dos indivíduos de interesse. 
Tabela 3: Distribuição das notas dos parâmetros avaliados nos troncos da população adulta de Tabebuia roseoalba, para a arborização da cidade de Maringá, PR.

\begin{tabular}{cccccc}
\hline Risco (nota) & Cavidades & $\begin{array}{c}\text { Orifícios de } \\
\text { insetos } \\
\text { (Cupins) }\end{array}$ & Fungos & Cancro & $\begin{array}{c}\text { Injúrias } \\
\text { mecãnicas }\end{array}$ \\
\hline $\mathbf{0}$ & 472 & 477 & 484 & 393 & 309 \\
$\mathbf{1}$ & 5 & 0 & - & 23 & 70 \\
$\mathbf{2}$ & - & 4 & - & 29 & 76 \\
$\mathbf{3}$ & 6 & 1 & - & 18 & 21 \\
$\mathbf{4}$ & - & 0 & - & 11 & 7 \\
$\mathbf{5}$ & 3 & 4 & 2 & 12 & 3 \\
\hline Total & $\mathbf{4 8 6}$ & $\mathbf{4 8 6}$ & $\mathbf{4 8 6}$ & $\mathbf{4 8 6}$ & $\mathbf{4 8 6}$ \\
\hline
\end{tabular}

Os resultados da tabela 3 demonstram poucas notas ruins (4 e 5). O parâmetro relacionado aos cancros foi o que mais demonstrou problemas sérios nos troncos das árvores analisadas. De Angelis et al. (2007) avaliaram a ocorrência de cancro na arborização urbana de dois bairros em Maringá, relatando que o mesmo esta diretamente relacionado a pequenos atos de vandalismo que causam ferimentos como, galhos quebrados, fixação de cartazes, utilização dos troncos como local para "estacionar" bicicletas e motos, estas ações antrópicas deixam espaços abertos para a entrada dos patógenos causadores do cancro.

A pouca existência de orifícios de insetos (cupins), cavidades e fungos nos troncos se justifica pelo fato da maioria das árvores de Tabebuia roseoalba em Maringá serem de plantios recentes, ou seja, são muito poucos os indivíduos senis, e estas manifestações aparecem quando existe matéria em decomposição nas árvores.

\section{Análise dos parâmetros de avaliação na base do tronco das árvores}

A tabela 4 demonstra os resultados das notas (riscos) avaliados em vários parâmetros verificados nas bases dos troncos das árvores dos indivíduos de interesse. 
Tabela 4: Distribuição das notas dos parâmetros avaliados nas bases dos troncos da população adulta de Tabebuia roseoalba, para a arborização da cidade de Maringá, PR.

\begin{tabular}{ccccccc}
\hline Risco (nota) & Cavidades & Fungos & $\begin{array}{c}\text { Espaço } \\
\text { permeável }\end{array}$ & Neilóide & $\begin{array}{c}\text { Raízes } \\
\text { cortadas }\end{array}$ & $\begin{array}{c}\text { Elevação e } \\
\text { fissuras nas } \\
\text { calçadas }\end{array}$ \\
\hline $\mathbf{0}$ & 478 & 482 & - & 343 & 483 & 451 \\
$\mathbf{1}$ & 4 & - & 163 & - & 1 & - \\
$\mathbf{2}$ & 0 & - & - & - & 0 & - \\
$\mathbf{3}$ & 2 & - & 244 & - & 2 & - \\
$\mathbf{4}$ & 0 & - & - & - & 0 & - \\
$\mathbf{5}$ & 2 & 4 & $\mathbf{7 9}$ & 143 & 0 & 35 \\
\hline Total & $\mathbf{4 8 6}$ & $\mathbf{4 8 6}$ & $\mathbf{4 8 6}$ & $\mathbf{4 8 6}$ & $\mathbf{4 8 6}$ & $\mathbf{4 8 6}$ \\
\hline
\end{tabular}

Os resultados da tabela 4 demonstram que a base do tronco foi onde os parâmetros analisados tiveram mais notas ruins em relação às copas e troncos analisados. Em relação ao espaço permeável 79 indivíduos (16,25\% dos indivíduos analisados) tiveram uma avaliação 5, ou seja, os troncos estão ocupando o espaço permeável por inteiro, sendo estas árvores ainda jovens isso futuramente acarretará problemas sérios, pois este espaço é importante para o bom desenvolvimento fisiológico da árvore, sendo que um espaço permeável adequado garante aeração do solo e disponibilidade de nutrientes para as plantas, esta condição contribui para uma melhor defesa da planta contra patógenos, pois uma planta saudável está menos susceptível ao ataque destes (BIONDI,1985).

Foi constatado também em 143 indivíduos (29,42\% dos indivíduos analisados) a ausência de neilóide, o que demonstra que muitos plantios realizados são feitos com covas muito profundas deixando as raízes em profundidade problemática para trocas gasosas e expansão destas.

Apesar das árvores de Tabebuia roseoalba não apresentarem indivíduos senis na arborização de Maringá, 35 indivíduos (7,20\% dos indivíduos analisados) já mostraram fissuras e elevações nas calçadas, isso é um indicativo de que o solo se encontra extremamente compactado, o que faz com que algumas raízes acabem por ficar superficiais, o que não é natural nesta espécie.

Continuando a sequência metodológica foi atribuída por indivíduo a maior nota obtida dentre os parâmetros de localização, copa, tronco e base tronco, dessa forma foi gerada a figura 2, demonstrando as porcentagens dessas notas em cada região analisada. Foram excluídos de serem matrizes qualquer indivíduo que tenha obtido uma nota 5 ou 4 em qualquer parâmetro analisado. 


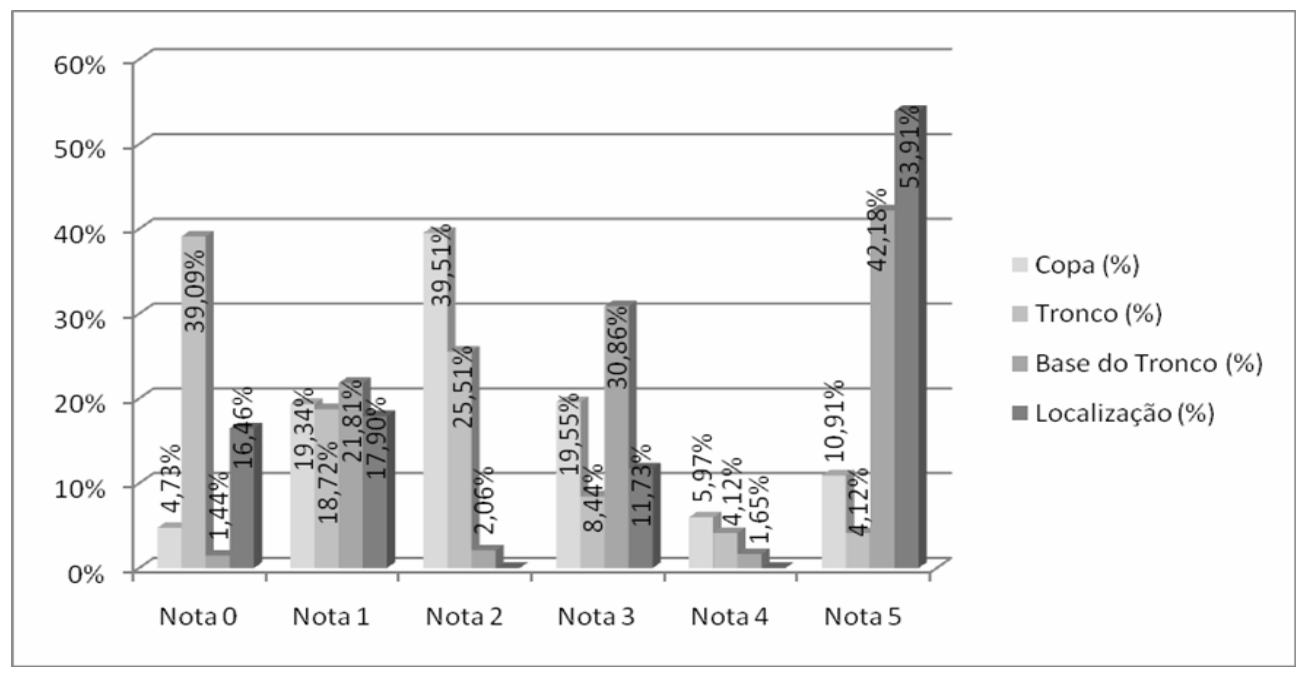

Figura 2. Distribuição das notas mais altas encontradas em cada região de análise (localização, copa, tronco e base), na população adulta de Tabebuia roseoalba.

$\mathrm{Na}$ região da copa tivemos a nota 2 constituindo 39,51\% das maiores notas atribuídas aos parâmetros analisados na copa, ou seja, a copa não apresentou muitos indivíduos com problemas sérios, sendo a maior porcentagem de uma nota que indica bons indicativos dos parâmetros analisados.

$\mathrm{Na}$ região do tronco a maior porcentagem de notas significativas foi referente a nota 3 que atingiu 30,86\% das notas mais altas atribuídas aos parâmetros analisados nessa região. A nota 3 demonstra casos de problemas regulares que acabam por não excluir nenhum indivíduo de ser matriz. Dessa forma a região do tronco não se mostrou com os problemas mais graves.

Na região da base do tronco a nota 5 correspondeu a 42,18\% das notas mais altas atribuídas a essa região (base do tronco), isso significa que $42,18 \%$ dos indivíduos que foram excluídos de serem matrizes ficaram assim designados por problemas sérios registrados em parâmetros analisados na base do tronco.

As análises sobre a localização das árvores, englobando vários parâmetros, foi a que obteve a maior porcentagem de notas ruins, sendo 53,91\% das notas mais altas atribuídas sendo nota 5, ou seja, a maior exclusão de indivíduos para não serem matrizes aconteceu devido a parâmetros relacionados a localização das árvores. 


\section{Número de Matrizes selecionadas}

Para calcular o número de matrizes necessárias, com representatividade genética, utilizou-se os trabalhos de Yamamoto et al. (2007) e Sebbenn e Seoane (2005) sobre índice de importância e tamanho efetivo de população.

A primeira questão a ser respondida foi a de quantas gerações são necessárias para se obter o número de mudas total, que serão utilizadas para substituição de outras árvores. Para o nosso estudo, este número ficou em 10.000 árvores de Tabebuia roseoalba, estabelecido pelo Plano diretor da cidade (PMM, 2007). Precisa-se de um planejamento para se chegar ao valor total de mudas, com variabilidade genética. Sebbenn (2002) considera como sendo apropriados os valores de tamanho efetivo de 50 e 100 (10 gerações) em curto prazo e em longo prazo 1000 (100 gerações).

Nesse estudo, trabalhou-se com a opção de curto prazo (10 gerações coletando-se 50 sementes) visto que as mudas são para substituição de indivíduos já senescentes, ou que oferecem risco de queda.

Segundo os cálculos de Yamamoto et al. (2007) a partir de 50 sementes coletadas por árvore se tem a representatividade genética de um indivíduo dentro da população. Os autores utilizaram este valor relativamente baixo, pelas constantes interferências que a árvore urbana sofre, reduzindo seu potencial de produção de sementes. Este estudo também utilizou o mesmo valor $n=50$, corroborando com a justificativa de Yamamoto et al, 2007. Sobre o grau de parentesco (q) Yamamoto et al. (2007) adotaram o valor de 0,5, mas segundo Bittencourt Júnior (2003), que trabalhou com a família Bignoniaceae, algumas espécies do gênero Tabebuia são auto-incompatíveis, não havendo indivíduos resultantes de auto-fecundação nas espécies Tabebuia umbellata, Tabebuia vellosoi e Tabebuia impetiginosa, sendo que esta característica tende a ser restrita ao gênero e pode incluir Tabebuia roseoalba. Com base nesses dados adotou-se o valor zero ( $q=0)$, ou seja, considerou-se que não há possibilidade de progênie vinda de auto-fecundação. Para Sebbenn (2002), o valor médio de endogamia para espécies arbóreas é de $10 \%(F=0,1)$. Yamamoto et al. (2007) estipularam um valor de endogamia três vezes maior $(F=0,3)$ do que Sebbenn (2002) em seus cálculos, podemos inferir que ele adota este valor por trabalhar com mais de uma espécie. Para este estudo utilizou-se o valor que Sebbenn (2002) recomenda, $10 \%(F=0,1)$. Com estes valores aplicados na fórmula (1), temos que o tamanho efetivo de uma progênie é: $\mathrm{Ne}=45,45$. Aplicando-se este valor na equação de quantidade necessária de matrizes (2), temos que $m=23,65$, ou seja, são necessárias 24 matrizes para uma população de 1.075 indivíduos de Tabebuia roseoalba. 


\section{Matrizes selecionadas}

A partir da análise dos dados coletados, foram excluídos indivíduos com notas 4 e 5 nos parâmetros analisados, dessa forma ficaram selecionados 102 indivíduos de Tabebuia roseoalba, que apresentaram bons parâmetros para serem matrizes. Na Tabela 5 vê-se a distribuição dos indivíduos selecionados pelos logradouros da cidade, 23 no total, dos quais, 16 árvores $(15,69 \%)$ se localizam no bairro Jardim Real, distribuídas pelas ruas: Rubi, Turquesa e Esmeralda. Isto se deve ao vasto plantio da espécie pela região, e também pela boa aceitação da espécie pelos moradores que vivem ali.

Tabela 5: Distribuição dos indivíduos de Tabebuia roseoalba selecionados para possíveis matrizes, nos logradouros de Maringá, PR.

\begin{tabular}{cc}
\hline Logradouros & N. Arvores \\
\hline 4816 & 11 \\
Abelardo J Cruz & 3 \\
Antonio Guimarães & 4 \\
Av. Guedner & 1 \\
Av. Joaquim D Molheirinho & 2 \\
Av. Tuiuti & 9 \\
Camomila & 4 \\
Carneiro Leão & 6 \\
Darville A. Huergo & 3 \\
Distrito Federal & 2 \\
Esmeralda & 7 \\
João Custodio Pereira & 7 \\
Londrina & 2 \\
Nestor N Souza & 5 \\
Pintassilgo & 1 \\
Pion. O Mariani & 12 \\
Pion. Regina N Cerestino & 5 \\
Quartzo & 3 \\
Rio Itapemirim & 2 \\
Rio Japuratuba & 2 \\
Rosa Rubini & 2 \\
Rubi & 102 \\
Turquesa & \\
ToTAL & 2 \\
\hline
\end{tabular}


Seguindo os cálculos e a ordem de prioridade de parâmetros, utilizou-se o Índice biométrico para selecionar as 24 matrizes, as quais encontram-se listadas nas tabelas 6 e 7, que demonstram os resultados adquirido nas várias avaliações feitas. 
Tabela 6: Matrizes selecionadas com identificação do logradouro, número da rua (ou referência), Número da árvore, valor biométrico, e notas dos parâmetros referentes a análise da copa e tronco da população de Tabebuia roseoalba em Maringá, PR.

\begin{tabular}{|c|c|c|c|c|c|c|c|c|c|c|c|c|c|c|}
\hline Nome Via & $N^{\circ}$ na rua & Arvore $\mathrm{N}^{\circ}$ & $v b$ & $\begin{array}{c}\text { folhagem } \\
\text { rala /cor } \\
\text { anormal }\end{array}$ & $\begin{array}{l}\text { galhos } \\
\text { secos } \\
\text { (podres) }\end{array}$ & $\begin{array}{c}\text { galhos } \\
\text { angulados }\end{array}$ & $\begin{array}{c}\text { galhos } \\
\text { esguios }\end{array}$ & $\begin{array}{c}\text { Fungos } \\
\text { Copa }\end{array}$ & $\begin{array}{c}\text { poda } \\
\text { unilateral/ } \\
\text { drástica }\end{array}$ & $\begin{array}{c}\text { orifícios } \\
\text { de insetos }\end{array}$ & $\begin{array}{c}\text { Fungos } \\
\text { Tronco }\end{array}$ & cancro & $\begin{array}{c}\text { Injúrias } \\
\text { mecãnicas }\end{array}$ & $\begin{array}{c}\text { Cavidades } \\
\text { Tronco }\end{array}$ \\
\hline Av.Carneiro Leão & platão & 16 & 1,665 & 2 & 1 & 0 & 0 & 0 & 0 & 0 & 0 & 0 & 1 & 0 \\
\hline Av.Carneiro Leão & $s / n$ & 1 & 1,179 & 0 & 0 & 3 & 0 & 0 & 0 & 0 & 0 & 2 & 0 & 0 \\
\hline Antonio Guimarães & $s / n$ & 16 & 1,168 & 0 & 2 & 0 & 0 & 0 & 0 & 0 & 0 & 1 & 2 & 0 \\
\hline Carneiro Leão & garcia & 10 & 1,124 & 2 & 1 & 2 & 0 & 0 & 0 & 0 & 0 & 0 & 0 & 0 \\
\hline Av Tuiuti & 4229 & 11 & 0,969 & 0 & 0 & 0 & 0 & 0 & 0 & 0 & 0 & 0 & 0 & 0 \\
\hline Esmeralda & $472 a$ & 15 & 0,936 & 0 & 0 & 2 & 0 & 0 & 0 & 0 & 0 & 0 & 1 & 0 \\
\hline Turquesa & 119 & 17 & 0,924 & 0 & 1 & 1 & 0 & 0 & 0 & 0 & 0 & 0 & 0 & 0 \\
\hline Turquesa & 167 & 22 & 0,92 & 2 & 0 & 2 & 0 & 0 & 0 & 0 & 0 & 0 & 0 & 0 \\
\hline Rubi & $s / n$ & 15 & 0,911 & 0 & 0 & 2 & 0 & 0 & 0 & 0 & 0 & 0 & 0 & 0 \\
\hline Turquesa & 143 & 21 & 0,903 & 0 & 0 & 1 & 0 & 0 & 0 & 0 & 0 & 0 & 1 & 0 \\
\hline Turquesa & $s / n$ & 7 & 0,895 & 0 & 1 & 0 & 0 & 0 & 0 & 0 & 0 & 0 & 1 & 0 \\
\hline Av.Carneiro Leão & 331 & 6 & 0,858 & 0 & 0 & 2 & 0 & 0 & 0 & 0 & 0 & 2 & 0 & 0 \\
\hline Av Tuiuti & $s / n$ & 2 & 0,844 & 1 & 0 & 0 & 0 & 0 & 0 & 0 & 0 & 1 & 0 & 0 \\
\hline Av.Carneiro Leão & 459 & 11 & 0,842 & 2 & 2 & 0 & 0 & 0 & 0 & 0 & 0 & 0 & 0 & 0 \\
\hline Rio Itapemirim & $\mathrm{s} / \mathrm{n}$ & 8 & 0,842 & 0 & 1 & 0 & 0 & 0 & 0 & 0 & 0 & 0 & 0 & 0 \\
\hline Av.Carneiro Leão & 803 & 18 & 0,797 & 0 & 0 & 0 & 0 & 0 & 0 & 0 & 0 & 2 & 0 & 0 \\
\hline Turquesa & $s / n$ & 16 & 0,787 & 1 & 2 & 1 & 0 & 0 & 0 & 0 & 0 & 2 & 0 & 0 \\
\hline Av Tuiuti & 4382 & 5 & 0,78 & 0 & 0 & 0 & 0 & 0 & 0 & 0 & 0 & 1 & 0 & 0 \\
\hline 4816 & $s / n$ & 21 & 0,758 & 0 & 0 & 0 & 2 & 0 & 0 & 0 & 0 & 0 & 2 & 0 \\
\hline Av Tuiuti & $s / n$ & 7 & 0,757 & 0 & 0 & 0 & 0 & 0 & 0 & 0 & 0 & 0 & 0 & 0 \\
\hline Rubi & $s / n$ & 33 & 0,733 & 0 & 0 & 0 & 0 & 0 & 0 & 0 & 0 & 0 & 0 & 0 \\
\hline Turquesa & $s / n$ & 5 & 0,73 & 1 & 2 & 0 & 0 & 0 & 0 & 0 & 0 & 0 & 2 & 0 \\
\hline Distrito Federal & 1089 & 6 & 0,728 & 0 & 1 & 1 & 0 & 0 & 0 & 0 & 0 & 0 & 0 & 0 \\
\hline Esmeralda & $838 \mathrm{~b}$ & 26 & 0,721 & 2 & 0 & 2 & 0 & 0 & 0 & 0 & 0 & 0 & 1 & 0 \\
\hline
\end{tabular}


Tabela 7: Matrizes selecionadas com identificação do logradouro, Número da árvore, notas dos parâmetros referentes a análise da base do tronco da e notas finais por grupo analisado e por indivíduo na população de Tabebuia roseoalba em Maringá, PR.

\begin{tabular}{|c|c|c|c|c|c|c|c|c|c|c|c|c|c|}
\hline Logradouro & Arvore $N^{\circ}$ & $\begin{array}{c}\text { Cavidades } \\
\text { Base }\end{array}$ & $\begin{array}{l}\text { Brotação } \\
\text { epicórmica }\end{array}$ & Neilóide & $\begin{array}{c}\text { Fungos } \\
\text { Base }\end{array}$ & $\begin{array}{c}\text { Espaço } \\
\text { permeável }\end{array}$ & $\begin{array}{l}\text { Elevação } \\
\text { do solo e } \\
\text { fissuras }\end{array}$ & $\begin{array}{l}\text { Raízes } \\
\text { cortadas }\end{array}$ & Localização & Copa & Tronco & Base & Final \\
\hline Av.Carneiro Leão & 16 & 0 & 0 & 0 & 0 & 3 & 0 & 0 & 0 & 2 & 1 & 3 & 3 \\
\hline $\begin{array}{l}\text { Av.Carneiro Leão } \\
\text { Antonio }\end{array}$ & 1 & 0 & 0 & 0 & 0 & 3 & 0 & 0 & 0 & 3 & 0 & 3 & 3 \\
\hline Guimarães & 16 & 0 & 0 & 0 & 0 & 3 & 0 & 0 & 3 & 2 & 2 & 3 & 3 \\
\hline Carneiro Leão & 10 & 0 & 0 & 0 & 0 & 3 & 0 & 0 & 0 & 2 & 0 & 3 & 3 \\
\hline Av. Tuiuti & 11 & 0 & 0 & 0 & 0 & 1 & 0 & 0 & 3 & 2 & 0 & 1 & 3 \\
\hline Esmeralda & 15 & 0 & 0 & 0 & 0 & 1 & 0 & 0 & 3 & 2 & 1 & 1 & 3 \\
\hline Turquesa & 17 & 0 & 0 & 0 & 0 & 1 & 0 & 0 & 1 & 1 & 0 & 1 & 1 \\
\hline Turquesa & 22 & 0 & 0 & 0 & 0 & 1 & 0 & 0 & 1 & 2 & 0 & 1 & 2 \\
\hline Rubi & 15 & 0 & 0 & 0 & 0 & 1 & 0 & 0 & 3 & 3 & 0 & 1 & 3 \\
\hline Turquesa & 21 & 0 & 0 & 0 & 0 & 1 & 0 & 0 & 1 & 1 & 1 & 1 & 1 \\
\hline Turquesa & 7 & 0 & 0 & 0 & 0 & 3 & 0 & 0 & 0 & 1 & 1 & 3 & 3 \\
\hline Av.Carneiro Leão & 6 & 0 & 0 & 0 & 0 & 3 & 0 & 0 & 0 & 2 & 2 & 3 & 3 \\
\hline Av. Tuiuti & 2 & 0 & 0 & 0 & 0 & 1 & 0 & 0 & 0 & 1 & 1 & 1 & 1 \\
\hline Av.Carneiro Leão & 11 & 0 & 0 & 0 & 0 & 3 & 0 & 0 & 0 & 2 & 0 & 3 & 3 \\
\hline Rio Itapemirim & 8 & 0 & 0 & 0 & 0 & 3 & 0 & 0 & 1 & 1 & 0 & 3 & 3 \\
\hline Av.Carneiro Leão & 18 & 0 & 0 & 0 & 0 & 3 & 0 & 0 & 0 & 2 & 2 & 3 & 3 \\
\hline Turquesa & 16 & 0 & 0 & 5 & 0 & 3 & 0 & 0 & 0 & 2 & 2 & 3 & 3 \\
\hline Av. Tuiuti & 5 & 0 & 0 & 0 & 0 & 1 & 0 & 0 & 0 & 1 & 0 & 1 & 1 \\
\hline 4816 & 21 & 0 & 0 & 0 & 0 & 3 & 0 & 0 & 0 & 2 & 3 & 3 & 3 \\
\hline Av. Tuiuti & 7 & 0 & 0 & 0 & 0 & 1 & 0 & 0 & 0 & 2 & 0 & 1 & 2 \\
\hline Rubi & 33 & 0 & 0 & 0 & 0 & 1 & 0 & 0 & 0 & 0 & 0 & 3 & 3 \\
\hline Turquesa & 5 & 3 & 0 & 0 & 0 & 3 & 0 & 0 & 0 & 2 & 2 & 3 & 3 \\
\hline Distrito Federal & 6 & 0 & 0 & 0 & 0 & 1 & 0 & 0 & 1 & 1 & 0 & 1 & 1 \\
\hline Esmeralda & 26 & 0 & 0 & 0 & 0 & 1 & 0 & 0 & 1 & 2 & 1 & 1 & 2 \\
\hline
\end{tabular}


Nas árvores escolhidas para matrizes, todas as notas de todos os parâmetros foram abaixo de 4 , demonstrando que estão sem problemas determinados pela análise de campo como sérios.

Segundo o Plano Diretor de Maringá (PMM, 2007), está programado que a representatividade da população de Tabebuia roseoalba passe de 1,15\% atual para 6,0\%. Esta mudança ocorrerá gradativamente, conciliada com a produção de mudas a curto prazo (10 gerações aproximadamente) se for utilizado o valor de 50 sementes e 24 matrizes, pode levar 8,3 anos (situação hipotética com 100\% de germinação) para se completar as 10.000 árvores previstas no Plano. Por haver mais 78 indivíduos com possibilidades de se tornarem matrizes, se houver necessidade de aumentar a produção de mudas e com isso diminuir o prazo para se chegar as 10.000 árvores, recomenda-se que seja aumentado o número de matrizes e não o número de sementes a serem coletadas das 24 matrizes.

\section{CONCLUSÕES}

Através da análise dos vários parâmetros, pode-se avaliar bem as condições da população de Tabebuia roseoalba da cidade de Maringá-PR. Esta se mostrou com indivíduos ainda recentes na arborização da cidade, principalmente por este fator não foram encontradas grandes porcentagens de problemas fitossanitários comprometedores. Foi considerado a localização destas árvores que muitas vezes se mostrou fora do padrão de planejamento proposto pelo Plano Diretor de Arborização Urbana de Maringá.

Houve predomínio de três logradouros na localização das matrizes, sendo a rua Turquesa, Av. Carneiro Leão e Av. Tuiuti.

O índice biométrico se mostrou um parâmetro bom para prioridades de estabelecimento das matrizes, pela simplicidade, rapidez e pelos resultados apresentarem um bom grau de discernimento quanto ao desenvolvimento da árvore.

Foram selecionadas 24 matrizes com os parâmetros analisados, distribuídos em quatro logradouros da cidade de Maringá. Este estudo demonstrou que a determinação de matrizes urbanas através do sistema de pontuação proporciona eficiência para se eleger indivíduos por meio de vários parâmetros quali-quantitativos simultaneamente. Mantendo-se atualizado este banco de dados, pode-se manejar com estratégia a população para uma futura troca ou incremento das matrizes, aumentando a variabilidade genética. 


\section{REFERÊNCIAS BIBLIOGRÁFICAS}

BIONDI, D. Diagnóstico da Arborização de Ruas da Cidade de Recife. Curitiba, UFPR., 1985. 167 f. Dissertação (Mestrado) Universidade Federal do Paraná, Curitiba, 1985.

BITTENCOURT JÚNIOR, N.S. Auto-incompatibilidade de ação tardia e outros sistemas reprodutivos em Bignoniaceae. 2003. 286 p. Tese. (Doutorado em Biologia Vegetal) Universidade Estadual de Campinas, Campinas.

CASTRO, R.M.; DE ANGELIS, B.L.D. Estudo comparativo do cancro em árvores de acompanhamento viário em duas áreas distintas - Central e residencial - na cidade de Maringá-PR. Maringá, 2004. 42 p. Dissertação (Mestrado em Agronomia). Universidade Estadual de Maringá.

COCKERHAM, C.C. Variance of gene frequency. Evolution, v.23, p.72-84, 1969.

DE ANGELIS, B.L.D., CASTRO, R.M., DE ANGELIS NETO, G. Ocorrência do cancro de tronco em árvores de acompanhamento viário na cidade de Maringá, Paraná. Revista da Sociedade Brasileira de Arborização Urbana, v.2, n.2, p.31- 44, 2007.

EMBRAPA, Empresa Brasileira de Pesquisa Agropecuária. Centro Nacional de Pesquisa de Solos. Sistema brasileiro de classificação de solos. 2 ed. Rio de Janeiro, 2006. 306 p.

IBGE, Instituto Brasileiro de Geografia e Estatística. Planilha sobre populações residentes segundo os municípios, em 01 de abril de 2007. Disponível em: <http://www.ibge.gov.br/home/estatistica/populacao/contagem2007/popmunic2007layoutTCU1411200 7.xls > Acesso em: 05 mai, 2008.

LORENZI, H. Árvores brasileiras; manual de identificação e cultivo de plantas arbóreas nativas do Brasil. Nova Odessa: Plantarum, 352p.1992. (Volume 1)

MAACK, R. Geografia física do Estado do Paraná. Curitiba: BADEP, 1968. 350 p.

MILANO, M.S. Avaliação quali-quantitativa e manejo da arborização urbana: exemplo de Maringá -PR. 1988, 120p. Tese (Doutorado em Engenharia Florestal) Universidade Federal do Paraná, Curitiba.

PMM, Prefeitura Municipal de Maringá. Plano diretor de arborização de vias públicas de MaringáPr. 2007.

SAMPAIO, A.C.F. Análise da arborização de vias públicas das principais zonas do plano piloto de Maringá- PR. 2006. 150p. Dissertação. (Mestrado em Geografia) Universidade Estadual de Maringá, Maringá. 
SEBBENN, A.M. Número de árvores matrizes e conceitos genéticos na coleta de sementes para reflorestamentos com espécies nativas. Revista do Instituto Florestal, v.14, n.2, p.115- 132, 2002.

SEBBENN, A.M.; SEOANE, C.E.S. Estimativa de tamanho efetivo de endogamia por marcadores genéticos. Revista Árvore, Viçosa, v.29, n.1, p.1-7, 2005.

SEITZ, R.A. Avaliação visual de árvores de risco (AVR). Mini-curso In: X CBAU - CONGRESSO BRASILEIRO DE ARBORIZAÇÃO URBANA, Maringá, 2006. Anais. Maringá, 2006. CD-ROM

SILVA FILHO, D.F.; PIZETTA, P.U.C.; ALMEIDA, J. B. S. A. Banco de dados relacional para cadastro, avaliação e manejo da arborização em vias públicas. Revista Árvore, v. 26, n. 5, p. 629$642,2002$.

VELOSO, H.P.; GÓES-FILHO, L. Fitogeografia brasileira - classificação fisionômico-ecológica da vegetação neotropical. Boletim Técnico do Projeto Radambrasil, Série Vegetação v.1, p.180,1982 .

YAMAMOTO, M.A.; SOBIERAJSKI, G.R ; SILVA FILHO, D.F.; COUTO, H.T.Z. Árvores Matrizes de Tabebuia pentaphyla (I.) Hemsl. (Ipê-de-El-Salvador) e Caesalpinia pluviosa DC. (Sibipiruna) em área urbana, selecionadas por meio de índice de importância. Revista da Sociedade Brasileira de Arborização Urbana, v.2, n.3, p.3-31, 2007. 